\title{
STUDY ON MONGOLIAN FOREST STAND DYNAMICS USING MATHEMATICAL MODELING
}

\author{
Khulan M. ${ }^{1 *}$ and Liu Junchang ${ }^{2}$ \\ 1. School of Economics and Management, BJFU, Beijing, China \\ 2. School of Economics and Management, BJFU, Beijing, China \\ *corresponding author: e-mail: khulan.m@seas.num.edu.mn
}

\begin{abstract}
A Global warming, climate change and negative human activities are expected to directly and negatively influence Mongolia's forest resource area and quality [21]. In 2015, Mongolian forested area was 12,188.2 thousand hectare and in compared with the forested area in 2010, it has decreased by 864.5 thousand hectare. The important causes of deforestation and forest degradation are fire, improper commercial logging, illegal collection of wood for construction and fuel wood, overgrazing, mining activity, and damage by pests and diseases. Mongolian forest stand is not only decreasing in quantity, but also forest age class has been changing into maturity forest classification in recent years. The maturity forest resource has counted for 74 percent of total forest resource is in National Forest Inventory, 2016.

There are few study for Mongolian forest stand dynamics and this work is first research that used stochastic process to predict forest stand dynamics in Mongolian case. This paper considered the main factors such as Climate factors and Socio-Economic factors in predicting forest stand dynamics. The factors are chosen based on real situation of forest resource's changes in Mongolia. The study has estimated coefficients of relationship between forest resource and main factors, as well as main factors and their explanatory variables, using suitable regression model for all estimation. Moreover, Markov chain process has been used to extracted future dynamic of forest stand by age class structure based on imbalanced age structure of total forest resource today.

The result of this paper shows that the most important factors that influenced the future forest stand changes are forest fire, commercial logging and afforestation. The estimated model results shows the forest fire will be decreased (9\%), commercial logging will be increased (25\%) and reforestation will be increased (30\%) by 2030. Specially, this paper presented that forest resource will be decreased by 13 percent in future 15 years. Additionally, this decrease is consist of forest age structure changes which is young aged forest would be increased by $27 \%$, middle aged forest would be decreased by 15\%, maturing forest would be decreased by $39 \%$ and maturity forest would be decreased by $16 \%$ in 2030.
\end{abstract}

Keywords: Forest stand dynamics, Forest age structure, Transition matrix; 


\section{INTRODUCTION}

The sustainable forest management has been developing throughout the world to keeping a balance of environment, economic and social when people is using natural resources by optimal and suitable management in the local country. Mongolian forest reserve lands comprise 18.3 million hectares, with 12.9 million hectares of the forest-covered area; this includes 10.5 million hectares of coniferous and hardwood forests, which is equivalent to 67 percent of the forest reserve. There is protected area is around $80 \%$ and utilization area is $20 \%$ Besides, Mongolian forest annual growth rate is $10.5 \%$ that is compared to an average of the world's growth rate 5 times less.

Statics on deforestation is confusing and often conflicting, it has been estimated [37] that Mongolia lost about 1.6 million ha of forest 1950-1980, 660 thousand ha 1990-2002 and a further 32 million ha 2000-2015. The major of causes of forest loss have been unsustainable forest harvesting (both permitted and illegal) for timber and fuel wood, forest fire, insect and disease, mining, uncontrolled grazing and long-term fluctuations [40]. An unsustainable management has been affected in not only decrease of the forest resource, its effecting in forest age structure that it has been estimated that Mongolian forest consisting of $72 \%$ of maturity forest, $12 \%$ classed as maturing, $11 \%$ classed as middle aged and less than 5\%

\section{METHODOLOGY}

In this study, we developed some mathematical models that are including regression model and Markov chain process.

\section{$\underline{\text { Regression models }}$}

First, we have dealing with linear regression models which estimated some problems such as determined main factors of forest resource's changes, predicted main factors future dynamic and forest stand dynamic in the future.

In a simple linear regression model, a single response measurement $\mathrm{Y}$ is related to classed as young trees [38]. Besides, there is 420 million cubic meters of dead standing trees and deadfall trees in total forest resource in 2015 year's statistic. This statistic shows that Mongolian forest has been used slightly and inappropriate. Main causes are global warming level is 3 times more than world average warming level, and forest management has some weakness such as unregulated use, over- use, and inadequate protection.

The main objective of this study is that to find the quantitative influence of the main factors of forest stand dynamics and to predict future changes in order to provide the information for sustainable management of forest stand in Mongolia.

Moreover, to know factors which are climate and socio-economical factors have been affecting in forest resource changes, as well as to analyze dynamic patterns of these main factors in future. The result of the study will provide information for decision makers to manage harvest permission and silviculture sustainability in long-term.

We believe that based upon results and recommendations which were done during the study of forest dynamics would help to implement appropriate management for a policy-makers and decision makers to protect and to control appropriate consumption of forest resource and biomass.

a single predictor (covariate, regressor) $\mathrm{X}$ for each observation.

Over recent years, negative influences on forests, such as climate change, forest fire, harmful effects of human activities on biological systems, and harmful effects of insect and disease propagation have caused hotbeds of damaging activity that have led to critical injury.

In this paper, our general model of forest stand dynamic should be expressed by 
equation (1).

$$
Y=\beta_{0}+\beta_{1} * X_{1}+\beta_{2} * X_{2}+\beta_{3} * X_{3}
$$

where,

$$
\begin{aligned}
& Y-\text { Forest Covered area, (ha) } \\
& X_{1}-\text { Burnt forest area, (ha) } \\
& X_{2}-\text { Harvested wood from forested area, (m3) } \\
& X_{3}-\text { Reforested area, (ha) }
\end{aligned}
$$

Accordingly, we estimated future value of each main factor's changes which are determined in equation (1).

\section{Prediction of factor $X_{1}$ which is forest fire.}

A fire impact is huge in forest and steppe area in Mongolia. Wild land fire in Mongolia is mainly caused by humans [22].There are the factors such as fire from neighbor countries, illegal logging, private tourisms are the reason of forest fire. Besides, the influence of climate changing is the reason to distribute in large area. About 95 percent of steppe and forest fires in Mongolia are caused by human

activities [12]. The impact of global warming is observed in Mongolia more than most of the regions in the world. The annual mean temperature of Mongolia increased by $2.14^{\circ} \mathrm{C}$ during the last 70 years. The spring is most dry season and most of percent of forest fire was burnt in spring season.

In Mongolia, average precipitation has been decreasing by $0.01 \mathrm{~mm} /$ year. A high temperature and dry air are keeping up the condition of to burn fire fast distribute in large area.

Therefore, Forest fire has explained by equation (2),

$$
X_{1}=\alpha_{0}+\alpha_{1} w_{1}+\alpha_{2} w_{2}+\alpha_{3} w_{3},
$$

where,

$$
\begin{aligned}
& X_{1}-\text { Burnt forest area, (ha) } \\
& W_{1} \text {-Average temperature, }\left(3,4 \text { and } 5^{\text {th }}\right. \text { months) } \\
& W_{2} \text {-Average precipitation, }\left(3,4 \text { and } 5^{\text {th }}\right. \text { months) } \\
& W_{3}-\text { Illegal logging, (ha) }
\end{aligned}
$$

\section{Prediction of factor $X_{2}$ which is}

\section{Commercial Logging}

A quantity of harvest from forest is determined by wood consumption, population growth and quantity of import wood in Mongolia. In statistical data, Mongolian population has been increasing constantly and wood consumption also has been increasing in past years [39].

Some general conclusions about the impacts of economic development and population growth on supply and demand for wood can be drawn in order to written in

$$
X_{2}=\gamma_{0}+\gamma_{1} * \ln (t)
$$

Mongolian forestry outlook study, 2010.

- Wood consumption for housing and fences will increase as the proportion of population in urban areas grows.

- Wood consumption will increase as a result of growth in the construction sector [21].

Therefore, in this paper we supposed that logging would be change by time affect due to population and wood consumption is increasing over the time.

There is logging dynamic expressed in nonlinear regression equation (3).

where,

\section{$X_{2}$ - Quantity of Logging, (ha)}

t- Time factor in including population and wood consumption effect, (yearly) 
3. Prediction of factor $X_{3}$ which is

Reforestation activity

Since 1971, reforestation activity has been regulated by the State Central Plan. Reforestation activities implemented totally in 100.3 thousand ha area, its only $30 \%$ of all the logged area in the country. In next regression model, quantity of reforestation was determined by government cost for forestry and reforestation. Because, there is reforestation has not been increasing following by increasing financial budget for forestry. It depends on several reasons such as seedling price has increased, seedling quality has been changing and other impacts.

$$
X_{3}=\theta_{0}+\theta_{1} \phi_{1}+\theta_{2} \phi_{2}+\theta_{3} \phi_{1} \phi_{2},
$$

where,

$$
\begin{aligned}
& X_{3}-\text { Reforestation area, }(\text { ha) } \\
& \phi_{1}-\text { Amount of money for reforestation (only budget of government) } \\
& \phi_{2}-\text { Average inflation rate, (yearly) } \\
& \phi_{1} \phi_{2}-\text { Interaction variable }
\end{aligned}
$$

This paper has developed 4 regression models to analyze forest dynamics and influencing factor in forest dynamics.

\section{A Markov chain process}

A Markov process is a random process for which the future (the next step) depends only on the present state. A Markov chain model was introduced in 1906 by Andrei Andreyevich Markov (1856-1922).

Recently, Markov process is useful in some fields such system dynamics are typical of those for queue lengths in call centers, stresses on materials, waiting times in production and service facilities, inventories in supply chains, parallel-processing software, water levels in dams, insurance funds, stock prices, forecasting labor supply and demand, forest dynamic, etc.

In this paper, we developed Markov chain process to predict of forest stand dynamics by age classes in future 15 years.

Suppose that forest resource has divided by such qualification in a group $k$. For example, forest resource has divided into a groups such as $E_{1}, E_{2}, \ldots, E_{k}$ and let be quantity of forest resource is determined by $Y(t)=\left(Y_{I}(t), Y_{2}(t), \ldots, Y_{k}(t)\right)$ in $t$ time.

In our case we assumed that $E_{p}, E_{2}, \ldots, E_{k}$, $k=5$. In other hand, we have divided into 5 groups forested area such that 4 kind of age classes and other 1 group is light forested area which is including forest burnt area, logged area etc.
There is Mongolian forest resource divided into 4 age structure such as Young aged forest is including replanted trees $(0-40$ years old $)$, middle aged forest (40-70 years old), maturing forest (70-120 years old) and maturity forest (under 120 years old).

We have several important assumptions about forest dynamic is written below.

- Some percentage of forest has been die from any age groups by some reasons such that forest fire, harvest, and others.

- Growth rate of forest is $10.1 \%$ per year. In other hand, after one year $10.1 \%$ of trees transfer into another age class.

- Old aged forest never transit into other age group.

- Reforestation depends on damaged forest area in that year. They has been planed about $34 \%$ of damaged area based on last 20 years statistic.

- The time unit is one year

Let's note $b(t), y(t), m(t)$ and $o(t)$ is young, middle, maturing and maturity forest in th year, respectively. We should write that a vector of age probability by vector $\mathrm{X}(\mathrm{t})$.

$$
\mathrm{Y}(\mathrm{t})=\left(\begin{array}{c}
b(t) \\
y(t) \\
m(t) \\
o(t) \\
l(t)
\end{array}\right)
$$


where, $\mathrm{X}(\mathrm{t})$ - total forest resource in $\mathrm{t}^{\text {th }}$ year.

We have calculated probabilities that are to destroy trees influenced by harvest, forest fire, and other factor's impact, to transit into other age class and to continue in actual age class. Noted, d- the probability that tree is destroyed, a- the probability that transition into other age groups, and 1-d-a - the probability that stay in a group.

The probability transition matrix is written below with using probability of each age class's dynamic.

$$
P=\left(\begin{array}{ccccc}
\left(1-0.66^{*} d_{b}-a_{b}\right) & a_{b} & 0 & 0 & 0.66^{*} d_{b} \\
0.34^{*} d_{y} & \left(1-d_{y}-a_{y}\right) & a_{y} & 0 & 0.66^{*} d_{y} \\
0.34^{*} d_{m} & 0 & \left(1-d_{m}-a_{m}\right) & a_{m} & 0.66^{*} d_{m} \\
0.34^{*} d_{o} & 0 & 0 & \left(1-d_{o}\right) & 0.66^{*} d_{o} \\
0 & 0 & 0 & 0 & 1
\end{array}\right)
$$

There is a sum of elements in a row should be equal to 1 in probability transition matrix according to theory.

Here, forest dynamic is going by written in each age classes.

$$
\begin{aligned}
& b(t+1)=\left(1-0.66 * d_{b}-a_{b}\right) * b(t)+0.34\left[d_{y} * y(t)+d_{m} * m(t)+\right. \\
& \left.+d_{o} * o(t)\right] y(t+1)=\left(1-d_{y}-a_{y}\right) * y(t)+a_{b} * b(t), \\
& m(t+1)=\left(1-d_{m}-a_{m}\right) * m(t)+a_{y} * y(t), \\
& o(t+1)=\left(1-d_{o}\right) * o(t)+a_{m} * m(t), \\
& l(t+1)=\left(0.66\left(d_{b}+d_{y}+d_{m}+d_{o}\right) * l(t) .\right.
\end{aligned}
$$

A Markov chain process can be written by process (5).

$$
Y(t+1)=Y(t) * P(t),
$$

where,

$P(t)$ - probability transition matrix of th year,

$Y(t)$ - a vector of forest age structure of th year.

\section{RESULTS AND DISCUSSION}

$\underline{\text { Data }}$

We used statistical yearly data from 1997 to 2016 and all of data were collected from different sources such as MEGDT, NSO, ArcGIS program, Statistics of FAO, and Statistics of World Bank.

An Estimation of Regression Models

We have developed model without impact of insect. Because forest fire is the one of the reasons which is increasing effects of insects in forested area of Mongolia. In other hand, its problem of multicollinearity and shows that strong correlation between forest fire and effect of insect can lead to large standard errors for the OLS estimates. Then, we considered regression model that is eliminated effect of insects and disease. 
Table.1 Information of Data

\begin{tabular}{|c|c|c|}
\hline Category & ID & Name \\
\hline \multirow{5}{*}{ Main Variables } & $\boldsymbol{Y}$ & Forest Covered Area \\
\hline & $X 1$ & Deforested area by Forest Fire \\
\hline & $x 2$ & Deforested area by Logging \\
\hline & $X 3$ & Degraded area by Insect and disease \\
\hline & $X 4$ & Reforested area \\
\hline \multirow{2}{*}{ Climate data } & $w 1$ & Air temperature \\
\hline & $w 2$ & Rainfall \\
\hline \multirow{6}{*}{ Social Economic data } & $w 3$ & Illegal logging \\
\hline & $t$ & Number of Population \\
\hline & $t$ & Wood consumption \\
\hline & $\phi_{1}$ & Government's budget for replant \\
\hline & $\phi_{2}$ & Inflation rate \\
\hline & $\phi_{1} \phi_{2}$ & Interaction variable \\
\hline \multirow{5}{*}{ Forest age stand } & $b(t)$ & Young aged forest ( $0-40$ years) \\
\hline & $y(t)$ & Middle aged forest (40-70years) \\
\hline & $m(t)$ & Maturing aged forest ( $70-120$ years) \\
\hline & $o(t)$ & Maturity forest (under 120 years) \\
\hline & $l(t)$ & Degraded forest area \\
\hline \multirow{3}{*}{ Probability Transition matrix } & $d$ & Probability to be destroyed forested area \\
\hline & $a$ & Probability to be transited into other age class \\
\hline & $1-d-a$ & Probability to be stayed in current age class \\
\hline
\end{tabular}

There is a result of regression analysis (1),

Table. 2 An estimation result of regression equation (1)

\begin{tabular}{cccc}
\hline$Y$ & Coef. & P>ItI & R-squared \\
- cons & 21917.27 & 0 & \\
$X_{1}$ & -0.09553 & 0.68 & 0.4 \\
$X_{2}$ & -10.2473 & 0.01 & \\
$X_{3}$ & 5.0014 & 0.98 & \\
\hline
\end{tabular}

However, an estimation of regression model shows coefficients and are statistical insignificant, these coefficients are practical significant. Therefore, this equation would be estimate forest stand dynamics of future.

In equation (2), we considered that average temperature and precipitation of March, April and May of yearly data from 1999 to 2016 . There is a dry season in Mongolia and most of the forest fire burnt during these three months. Also, factor of illegal logging could be expressed that human effect to burn fire in this equation. 


\begin{tabular}{crrr}
\hline \hline \multicolumn{4}{c}{ Table.3 An estimation result of regression equation (2) } \\
\hline$X_{1}$ & Coef. & $P>$ ItI & R-squared \\
- cons & -8614.54 & 0.04 & \\
$w_{1}$ & 515.26 & 0.03 & 0.83 \\
$w_{2}$ & -458.7 & 0.02 & \\
$w_{3}$ & 1.86 & \multicolumn{3}{c}{0.06} \\
\hline
\end{tabular}

In equation (3), quantity of logging logarithm function. In Mongolia, a quantity of expressed by time's factor that factor of logging should not be increase linear, because time would be including affect of population 86 percent of total forest resource is protection and consumption. Besides, there is used a forest area.

Table.4 An estimation result of regression equation (3)

\begin{tabular}{crrcc}
\hline$X_{2}$ & Coef. & $P>$ ItI & & R-squared \\
cons & -236763 & & 0 & 0.76 \\
\multicolumn{1}{c}{$t$} & 31217 & & 0 & \\
\hline
\end{tabular}

An estimation of regression equation (4) of total reforestation were planted by local shows that budget of government and inflation ownership and others [37]. Here, we assumed rate are affecting in reforestation. Note: that government budget for plantation by government has been planting 40-50 percent regressor $\phi_{1}$. of total reforestation in past years, others

\begin{tabular}{rrrc}
\multicolumn{4}{c}{ Table.5 An estimation result of regression equation (4) } \\
\hline$X_{4}$ & Coef. & $P>$ ItI & R-squared \\
cons & 7200.65 & 0 & \\
$\phi_{1}$ & 0.13 & 0.05 & 0.43 \\
$\phi_{2}$ & 52.85 & 0.03 & \\
$\phi_{1} \phi_{2}$ & $-6.09 E-06$ & 0.05 \\
\hline
\end{tabular}

However, a relationship between shows that forest resource will be increasing reforestation and inflation was estimated influenced by factors such as forest fire, positive relation, their negative impact was logging and reforestation. Table.6 shows that affected in interaction value is .

Finally, there is a prediction of equation predicted value of forest resource and main factors according to each model. (1). The result of prediction of forest resource

Table.6 Numerical value of historical data and prediction for 2030 
Figure. 1 shows that dynamics of logging, forest fire, reforestation and forest resource, respectively. The graphs are including statistical value of past years and predicted value of future years.

Forest resource would be decreased by climate factors, human effects, socio-economic factors in the future based on estimated result. Specially, impact of logging (both permitted and illegal) is affected high in changes of forest resource.

Figure.1 An estimated prediction of Forest resource, thousand ha
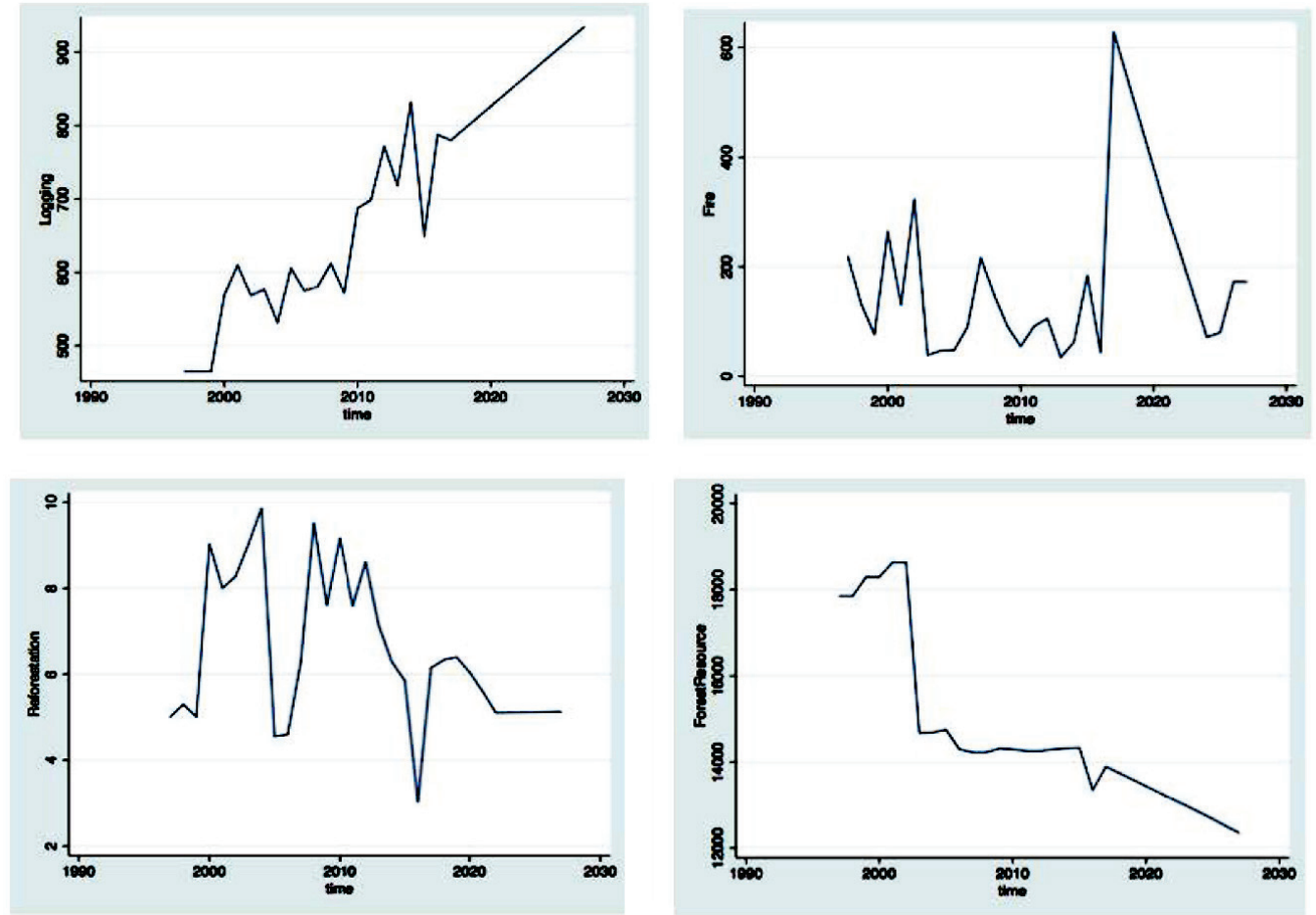

Source: STATA13.0

A Figure.1 presents that forest fire will be going decrease in future 10 years. The reasons of forest fire is from abroad $23.3 \%$, thunder $13.3 \%$ and others by human $65 \%$ were written in report of MEGD, 2008. In past years, government focusing on illegal logging and government started to own forest for

local people and villagers who are working in forest sector. These activities will be continued successfully, and in result of these activity illegal logging has been decreasing. As well as, dynamic of reforestation presented that reforestation is keeping up constantly around 4000-6000 hectare per year. 
An Estimation of Markov chain

In our case, probability transition matrix is determined by matrix P.

$$
P=\left(\begin{array}{ccccc}
0.89953 & 0.1 & 0 & 0 & 0.00047 \\
0.00561 & 0.88349 & 0.1 & 0 & 0.01089 \\
0.00603 & 0 & 0.88224 & 0.1 & 0.01171 \\
0.03848 & 0 & 0 & 0.88680 & 0.07471 \\
0 & 0 & 0 & 0 & 1
\end{array}\right)
$$

A Markov process (5) written in algebra notation:

$$
Y(t+1)=\left(\begin{array}{c}
b(t) \\
y(t) \\
m(t) \\
o(t) \\
l(t)
\end{array}\right) \times\left(\begin{array}{ccccc}
0.8995 & 0.1 & 0 & 0 & 0.0005 \\
0.0056 & 0.8835 & 0.1 & 0 & 0.0109 \\
0.0061 & 0 & 0.8825 & 0.1 & 0.0117 \\
0.0385 & 0 & 0 & 0.8868 & 0.0747 \\
0 & 0 & 0 & 0 & 1
\end{array}\right)
$$

According to result of a process (5), young to decreasing in next 15 years. Table.7 shows aged forest will be increasing slowly, middle, details of age class's changes in 2030. maturing and maturity aged forests will going

Table. 7 Numerical value of historical data and prediction

\begin{tabular}{lrrrr}
\hline & 1997 & 2007 & 2016 & $2030^{*}$ \\
Young aged forest & 85.7 & 68.3 & 79.0 & 101.0 \\
Middle aged forest & 1988.7 & 1584.8 & 1443.6 & 1217.2 \\
Maturing aged forest & 2138.7 & 1704.3 & 1704.7 & 1033.6 \\
Maturity forest & 13638.9 & 10869.0 & 10982.9 & 9306.2 \\
\hline
\end{tabular}

Figure.2 Estimated prediction of Forest age structure, (thousand ha)

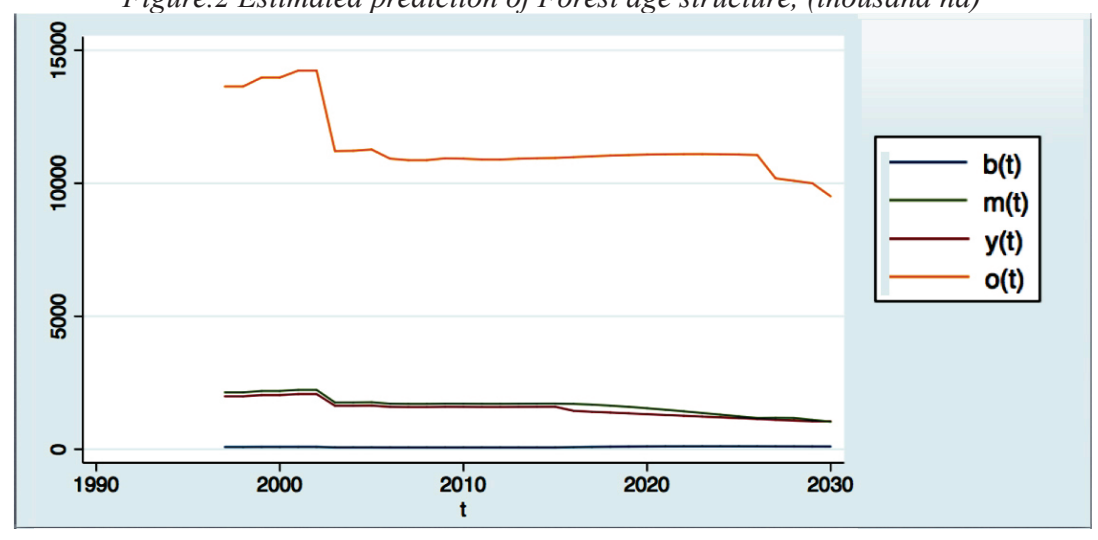

Source: Stata13.0 
Figure. 2 shows that forest resource will be decreased in totally, because of many reasons we have calculated in regression models. Markov process is showing that, old aged resource will be decreased rapidly, middle and maturing aged forest will be decreased slowly and young aged forest will be increased in the future.

\section{DISCUSSION}

We have obtained following results from estimations. Estimation is consisting of 2 sections such as to know main factors of forest resource changes and to predict future value using econometric model and to develop Markov chain of forest resource's age class dynamic.

In first section, estimated relationship between forest covered area and main factors which are forest fire, logging and reforestation. We have developed 4 different regression models for forest stand dynamics and their main factors dynamics.

The result of this research shows that relationship between forest stand dynamic and main three factors.

- There is negative and weak relationship between forest stand and forest fire.

- There is negative and strong relationship between forest stand and logged area.

- There is positive and weak relationship between forest stand and reforested area.

The result which is mentioned above is shown that direct relationship between forest stand and main three factors of forest sector. The result of estimation of regression models

\section{CONCLUSIONS AND RECOMMENDATION}

This paper aimed that to know relation between forest stand dynamics and environmental and socio-economical factors. Within the scope of the thesis, we have developed some mathematical models which regression models and Markov chain model. also has presented relationship between forest stand and other climatic factors and socioeconomic factors.

- Climate factors that is average temperature has been affecting positive for fire, and negative for forest stand.

- An average precipitation (rainfall) was one factor of climate factor in this thesis. Effect of precipitation is negative for forest fire and positive for forest stand.

- Illegal logging has been causing damage of forest resource during past years. Illegal logging affected positive for fire and negative for forest stand in empirical.

- The time factor is including effects of population and wood consumption in the future. A coefficient of the time factor has shown that there are relationship between logging and time factor is positive, and relationship between forest stand and time factor is negative.

- The budget of government for replant forest has been affecting positive for to be reforested area and total forest stand.

- An inflation rate was influenced for reforestation activity negative.

In second section, we developed Markov chain model to extract forest stand dynamics by age class. Result of Markov chain shows that young aged forest will be increasing including replant, middle aged forest, maturing forest and maturity aged forest will be decreased by forest fire, logging and impact of other factors.

Further, we estimated coefficients of four kinds of regression models. First regression model expressed that relationship between forest stand and main factors which forest fire, commercial logging and reforestation. Second one shows that relationship between forest fire 
and climatic factors which are temperature and precipitation, and socio-economic factor which is illegal logging. However, we used another methodology to estimate correlation between forest fore and climate impact that positive correlation between forest fire and average temperature and negative correlation between forest fire and precipitation in Mongolia suggest that same result with other papers about fire risk in Mongolia. The one of the main reason of fire is human negative activity [30]. In our case, according to positive correlation between fire and illegal logging, this fact was true. Third model presented that relationship between commercial logging and socio-economic factors that are population and wood consumption. A Result of relationship between logging and time factor shows that logging will be increased due to increasing population and wood consumption. The last regression model expressed that relationship between reforestation and socio-economic factors that are government budget for replant trees and inflation rate. At the end, we have predicted forest stand dynamics has influenced by result of these four regression models. Finally, we have estimated probability transition matrix for transit groups into each other. As well as, we predicted future dynamics of forest age class structure using prediction value which is estimated by regression models and a probability transition matrix.

In concluding, logged area was affected high in forest stand dynamics of Mongolia. Further, an effect of reforestation is weak in forest stand accordingly surviving rate is weak

\section{Acknowledgements}

I would like to thank all those people who extended their help and cooperation for this research. Specially, I am grateful for financial support and guidance provided by APFNet programme, professors and classmates of School of Economics and Management, for replanted trees. Mongolian forest stand would be decreased $13 \%$ in 2030 compared with current forest covered area as a our result of estimation. Then Markov process shows that young aged trees would be increased by $27 \%$, middle aged forest would be decreased by $15 \%$, maturing forest will be decreased by $39 \%$ and maturity forest will be decreased $16 \%$ in 2030 .

Based on our result, we recommended that government have to implement sustainable forest management in Mongolia, according to calculate real demand of wood consumption based on current forest resource and future prediction. This process should be manage many problems that are to decrease illegal logging, to keep balance of age structure, to rise income of households and forest ownership due to forest sanitation cutting activity. Also, Decision makers should to manage reforestation activity correspond closely to commercial logging at the same time. If could be managed sustainable both of reforestation activity and logging activity, would be kept balance of forest stand dynamics.

Limitation of study

The thesis focused on three main factors that are influencing forest stand dynamics. The study is not considered other factors such as uncotrolled grazing, mining effect, volunteer and other long-term fluctuations. Besides, probability transition matrix can be changed due to effect of other factors. Besides, in this paper we considered that general age structure of 4 groups.

Beijing Forestry University, and professors and colleagues of School of Engineering and Applied Sciences, National University of Mongolia for providing information, also sharing ideas and data, without which is would not have been completed. 


\section{REFERENCES}

[1] A Report on Legal and Illegal Timber Trade of Mongolia [R]. World Bank/WWF Alliance Project, 2002.

[2] Ahlback A J, Forestry in Mongolia [J]. International Forestry Review, Volume.1(1), 1999.

[3] Batsukh, Mongolian Forest Ecosystem [Z]. Ulaanbaatar, 2002

[4] Bayartaa, Fire environment, fire regimes, ecological role of fire common to country (or vegetation and fire characteristics of the region in which the country is located) [J]. Proceedings of I International Northeast Asia Forest Fire Conference and III International Meeting of the Northeast Asia Wildland Fire Network (28 to 30 September 2006, Khabarovsk, Russia), pp.105-110, 2002

[5] Ching-Rong Lin, Joseph Buongiorno, Managing Forests for Tree and Landscape Diversity Part I: Predictions with Markov-chain Models [J]. Multiple Use of Forests and Other Natural Resources, Volume 61 of the series Forestry sciences pp.137-157, 1999.

[6] Chuluunbaatar.Ts, Forest fire danger of Northern Mongolia [Z]. Ulaanbaatar, 1998, 25 pp.

[7] Chuluunbaatar. Ts, Forest Fires in Northern Mongolian Mountains [J]. International Forest Fire News No. 27, 92-97. 2002

[8] Chuluunbaatar, Ts. 2001. Forest fire danger and its reduction methods. Ulaanbaatar, $125 \mathrm{pp}$

[9] Chuluunbaatar.Ts.; Zoyoo.D. The forest fire influence on the forest phytocenoses of the Eastern Khuysugul [J]. In: Diversity of the plant cover within the Baikal Region. Ulan-Ude, pp.85, 1999.

[10] Dieterich, J.H. Fire Losses and Fire Control Programs [J]. International Forest Fire News No. 5, 4- 5. 1991.

[11] Dorjsuren Ch, Dugarjav Ch, Chuluunbaatar Ch, The Comprisal of Forestry. Ulaanbaatar, 2010.

[12] Elbegjargal Nasanbat, Ochirhuyag Lhamjav, Wild Fire Risk Map in The Eastern Steppe of Mongolia Using Spatial Multi-Criteria Analysis [J]. The International Archives of the Photogrammetry, Remote Sensing and Spatial Information Sciences, Volume XLI-B1, 2016 XXIII ISPRS Congress, 12-19 July 2016, Prague, Czech Republic

[13] Erdenesaikhan, N. Mongolia Fire Update. International Forest Fire News [J]. Freiburg, No. 15, 35- 36. 1996.

[14] Erdenesaikhan, N.; Erdenetuya, M. Forest and Steppe Fire Monitoring in Mongolia Using Satellite Remote Sensing [J]. International Forest Fire News No. 21, 71-74. 1999.

[15] Faculty of Forestry, Adaptation of Asia-Pacific Forests to Climate Change [EB/OL].

[16] FAO, Management and Climate Change: A Literaure Review [R]. 00153 Rome, Italy, 2012

[17] Forest Policy Statement. Resolution of the Government of Mongolia [Z]. No.248. 2001

[18] Goldammer, J.G. Fire Situation in Mongolia [J]. International Forest Fire News No. 26,75.

[19] Government of Mongolia, Amendments to the Law on Forests, Ulaanbaatar, 27 Jan 2002.

[20] HijabaYkhanbai, A Report on Legal and Illegal Timber Trade of Mongolia [R]. Economics of Environment and Sustainable Development, WWF Mongolia, 2000.

[21] Hijaba Ykhanbai, Mongolia Forestry Outlook Study [J]. Asia Pacific Forestry Sector Outlook Study II, FAO, 2010, APFSOS II/ WP/ 2009/ 21.

[22] Hiroshi Hayasaka, Murad Ahmed Farukh, Forest Fires in Mongolia-Analysis based on MODIS Hotspot and Weather Data, Japan, 2012

[23] International Journal of Knowledge, Innovation and Entrepreneurship [J]. Volume 2 No. 2, 2014, pp. 39-49

[24] Jaroslaw Oczki Nicelaus, Copernicus University, Forecasting Internal Labour Supply with a Use of Markov Chain Analysis [J]. Approved 31 July 2014, Poland, 2014.

[25] Jeffrey M.Wooldridge, Introductory Econometrics A Modern Approach, Fifth edition [Z]. Copyright $(2013$ Cengage Learning Asia Pte Ltd.

[26] Joseph Buongiorno, J Keith Gilles, Decision Methods for Forest Resource Management, An 
Imprint of Elsevier Science, copyright 2013, USA.

[27] Kent, Brain M Dress and Peter E, On the Convergence of Forest Stand Spatial Pattern Over Time: The Cases of Regular and Aggregated Initial Spatial Patterns [J]. Forest Science, Volume 26, Number 1, March 1989, pp. 10-22(12)

[28] Mathew T Jones, Estimating Markov Transition Matrices Using Proportions Data: An Application to Credit Risk [J]. International Monetary Fund, WP/05/219, November 2015.

[29] MEGD, Assessment report on Climate Change [R]. Ulaanbaatar, 2009

[30] MEGD, The report of Mongolian Environment and Conditions [R]. Ulaanbaatar, 2014.

[31] MEGD, Review of Mongolian Forest Sector [R], Ulaanbaatar, 2000

[32] MEGD, Report of Mongolian Natural Environment - 2006-2008s [R]. Ulaanbaatar, 2008

[33] MEGDT, Law and Legislation of Forestry [EB/OL] . http: //www.eIc.mn / forest resource / legalinfo .php

[34] Ministry of Environment, Green development, Report of Mongolian Natural Environment -2003 [R]. Ulaanbaatar, 2004.

[35] Ministry of Environment and Green Development, Forest sector financing flows and economic values in Mongolia [R]. UN-REDD program, 2013.

[36] Ministry of Environment, Green development, Report of Mongolian Natural Environment2008-2010s [R]. Ulaanbaatar, 2011

[37] Ministry of Environment, Green development and Tourism, Report of Mongolian Natural Environment - 2013-2014 [R]. Ulaanbaatar, 2015.

[38] MEGDT, Report of National Forest Enumeration, Ulaanbaatar, 2016

[39] National Statistical Office of Mongolia, Statistical Yearbook [R]. Ulaanbaatar, 1999-2016, Nineteen-volume book.

[40] Nicolas Crisp, John Dick, Micheal Mullins, Mongolian Forestry sector Review [R], The World Bank, 2004.

[41] Oyunsanaa Byambasuren, Fire and Stand Dynamics in Different Types of the West Khentey Mountains, Mongolia [J], dissertation, Gottingen 2011

[42] Peter Tarp, Matrix Modelling in Uneven-aged forest Management Planning [J]. Proceedings of the Biennial Meeting of the Scandinavian Society of Forest Economics Vantaa, Finland, May 2004.

[43] Review of Mongolian Forest Sector, MNE, Ulaanbaatar, 2000.

[44] Rodney J Kennan, Climate change umpacts and adaptation in forest management [J], Annals of Forest Science, Springer Verlag/EDP Sciences, 2015, 72 (2), pp.145-167.

[45] The World Bank, Mongolia Environmental Monitor [R]. The World Bank Office, Ulaanbaatar, 2002.

[46] Tsogtbaatar J, Forest Policy Development in Mongolia [J].Ulaanbaatar, 2004.

[47] University of British Columbiahttp. :/lasiapacific.forestry.ubc.ca.

[48] Yale University, Basics of Applied Sotchastic Process [EB/OL]. http://www.stat.yale. edu/ jtc5/251/readings/Basics\%20of\%20Applied\%20Stochastic\%20Processes_Serfozo.pdf 